\title{
MODELING OF PRECIPITATION BASED UPON THE UPPER-AIR SYNOPTICCIRCULATION TYPES
}

DOI: https://doi.org/10.18509/AGB.2018.07

UDC: $551.577 .3: 551.589 .1]: 519.246(495.3)$

\author{
Christina Patsika, Theodore Karacostas \\ Department of Meteorology and Climatology, Aristotelian University of Thessaloniki, Greece \\ Corresponding author: chrispa1991@yahoo.gr
}

Submitted: 23.02.2018, Accepted: 18.04.2018, Published: 30.09.2018

\begin{abstract}
Atmospheric circulation is one of the factors that greatly explain the variability of rainfall in an area. The objective on this study is to model the daily rainfall in the region of Thessaly-Greece, based on the prevailing upper-air synoptic circulation types of the atmosphere. The rainfall data used are daily records of rainfall measurements encountered at the meteorological station of Larissa for the period 1958-2015. Rainfall episodes of the examined period were classified into ten (10) upper-air synoptic circulation types, based on a subjective synoptic classification scheme. The relationships, between and among, these upperair synoptic circulation types and the associated rainfalls are studied and their characteristics are presented. The main upper-air synoptic circulation types, which are quite favorable to rainfall activities at the examined meteorological station of Larissa, appeared to be: the open Long Wave trough (L-1), the closed Long Wave trough (L-2), the Cut-Off Low (L-3) and the South-West flow (SW). From the analyses of the rainfall measurements of the aforementioned upper-air synoptic circulation types is concluded that the best fitted and the most appropriate distribution models are: the Gamma, Generalized Pareto, Weibull and Generalized Pareto, respectively. It is proven that these models describe the rainfall characteristics in the examined area very adequately.
\end{abstract}

Keywords: rainfall distribution model; synoptic circulation types; extreme value distributions; Thessaly-Greece.

\section{INTRODUCTION}

Thessaly is one of the largest rural areas in Greece, where rainfall is one of the most important sources of water for the cultivation and growth of crops. The knowledge of the rainfall regime and particularly of the rainfall probability distribution density functions could contribute towards better water management and decision making on crop irrigation plans.

The rainfall regime characteristics in an area is largely determined by the upper-air synoptic circulation types. Many synoptic classification schemes have been developed for different areas around the world with the aim to link together climate, weather and a wide range of environmental variables [19], [15], [10]. Over the major area of Greece, several researchers have developed and proposed specific and quite appropriatesynoptic classification schemes [11], [12], [16].

Atmospheric circulation is one of the factors that greatly explain the variability of rainfall in an area. Many researchers have attempted, mostly successfully, to relate the rainfall characteristics with the changes in atmospheric circulation [20], [21], [23], [7], [9], [17], [1], [18]. As an example, and focusing over the eastern Mediterranean region, there was detected a reduction in the frequency passage of depression activity, which reflected to an observed decrease of precipitation over the Greek region [14], [2], [6], [13].

An important tool in the thorough study of rainfall is the exact and theoretical knowledge of its probability distribution function. 
TheGamma distribution (2-parameter) function was generally proposed, as the most suitable distribution model for wet-days rainfall amount [22], [3]. Moreover, the Weibull and other exponential distribution functions have been proposed as equally appropriate distributions for daily rainfall behavior [25], [24], [5], [4].

However, the choice and adaptation of the most appropriate and suitable model requires careful interpretations since there is no complete agreement between theoretical and empirical distribution of data information. The choice of the appropriate model depends mainly on the characteristics of the variable displayed in the area of interest. The objective on this study is to determinate the best fit probability distribution models, based upon the upper-air synoptic circulation types, for the prediction of daily rainfall data in the region of Thessaly.

\section{DATA AND METHODOLOGY}

The data used to meet the aforementioned objective on this study are daily records of rainfall measurements encountered at the meteorological station of Larissa for the period 1958-2015. The rainfall episodes of the examined period were classified into ten (10) upper-air synoptic circulation types, based upon a subjective synoptic classification scheme proposed by Karacostas et al. [11] and Karacostas [12]. This synoptic classification is mainly based on the isobaric level of $500 \mathrm{hPa}$ and the position and orientation of the trough or ridge axes. A short description of the ten upper-air synoptic circulation types is briefly described as follows:

Zonal flow (ZON): The existence of this upper-air synoptic circulation type implies the existence of low amplitude trough to the northwest and a low amplitude ridge to the southeast of the area of interest.

North-West flow (NW): This flow arises from the presence of a long wave ridge located west-north-west of the area of interest and a long wave trough east-south-east. The result of this circulation is the transport of cold air masses from the north or northwest to the area of interest.

Open Long Wave trough (L-1): A characteristic of this type is the presence of a trough over the area of interest with its axis being either vertical or inclined without the appearance of a closed contour curve (Fig. 1a). Closed Long Wave trough (L-2): This type has similar features to L-1 with the difference to be found in the existence of at least one closed contour curve inside the trough (Fig. 1b).

Cut-Off Low (L-3): It is characterized by the closed contour lines, resulting in a cut-off low, completely separated from the main general circulation, being to the north of it. It is the mature stage of "L-1" and "L-2" types. The kinetic energy of the system has been transformed into dynamic energy and hence it remains almost stationary, with longer living time compares to "L-1" and "L-2" types (Fig. 1c).

South-West flow (SW):It is the result of the existence of a long wave trough located westsouth-west of the area of interest and a long wave ridge at its east-north-east (Fig. 1d).

Open Long Wave ridge (H-1): The characteristic of this upper-air synoptic circulation type is the presence of a long wave ridge over the area of interest with its axis being either vertical or inclined, without the appearance of a closed contour line.

Closed Long Wave ridge (H-2): This type has similar features to "H-1", with the difference to be found in the existence of at least one closed contour line inside the ridge.

Omega blocking $(\boldsymbol{\Omega})$ : It is the result of the proper arrangement of two low pressure systems and a high pressure one, in such a way to form the Greek letter " $\Omega$ ". This formation creates a blocking mechanism, as it prevents the movement of the low pressure systems eastwards, forcing them either to remain stationary in the west, or move either to the north or to the south of it.

Undetermined pattern (H-L): In this upperair synoptic circulation type there is no clear distinct pattern to categorize it to the previous synoptic types. Sometimes, these patterns are diffluent-like flow circulations with variable low intensity winds.

The study period is divided in two subperiods: 1958-2004 for the exploration and determination of the most suitable distribution models and 2005-2015 for the verification and confirmation of the identified models. Using the rainfall data of the exploratory period of 1958-2004, the rainfall characteristics and the 
relationships, between and among, the upperair synoptic circulation types and the associated rainfalls, are studied. The main upper-air synoptic circulation types which affect the rainfall behavior in the area, have been identified using two parameters, the index PI and the frequency of rainy days in each synoptic type. The PI is defined as the ratio of the mean daily rainfall amount of the wet days of each synoptic type, to the mean daily rainfall amount of all the wet days. If the ratio is greater than 1 then the daily rain amount is greater than the corresponding mean rain amount of the station [8], [9], [17].

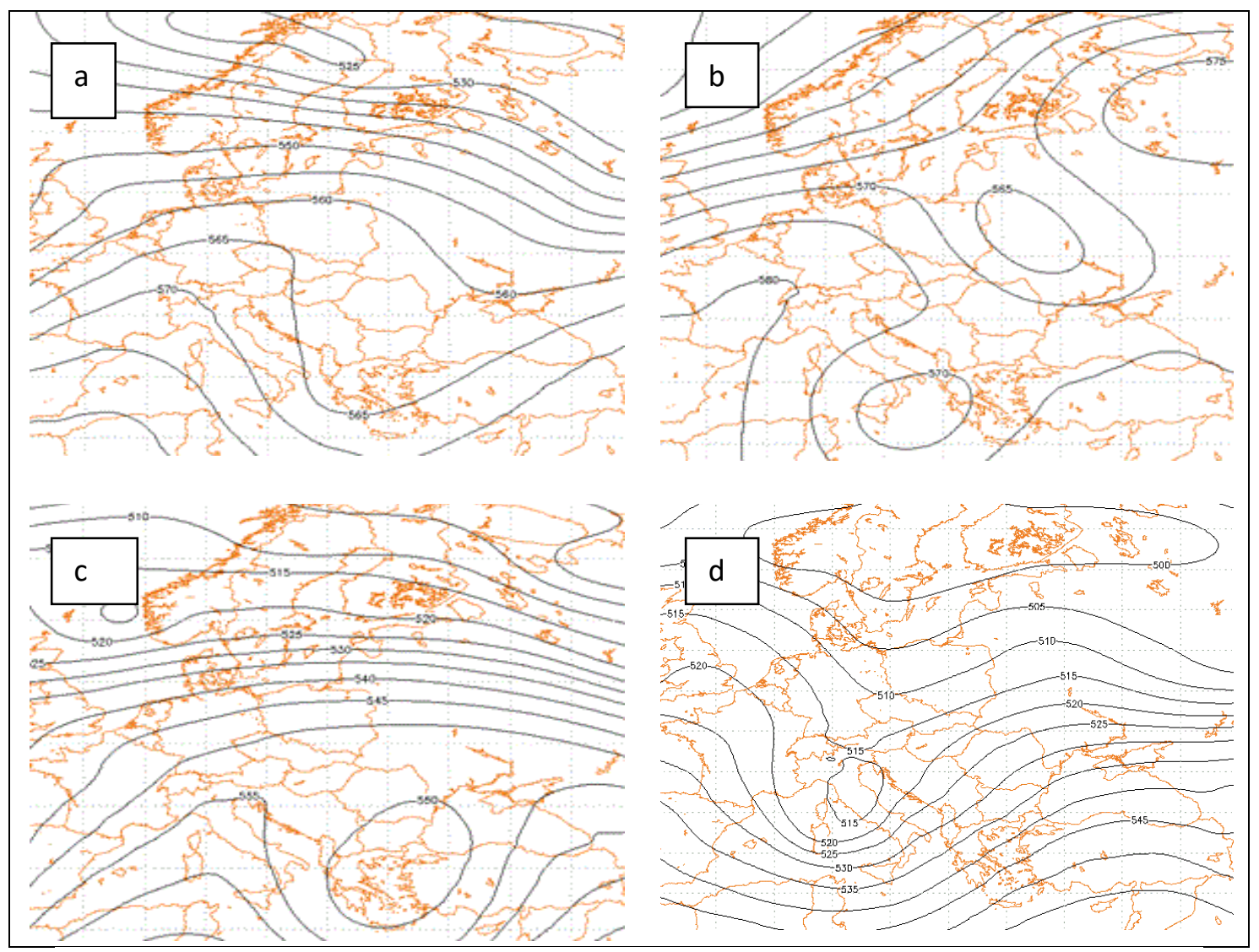

Figure 1. Schematic representation of 500hPa geopotential height (gpdam) for the main upper-air synoptic circulation types over the region of Thessaly: (a) Open Long Wave Trough (L-1), (b) Closed long Wave Trough (L-2), (c) Cut-off low (L-3) and (d) South-west flow (SW).

These parameters have been calculated for the total number of rainy days of the period 19582004 and on a monthly basis. Then, for the main circulation types, the choice of the best fit distribution models has been made using the following three statistical goodness of fit tests: the Kolmogorov-Smirnov, the AndersonDarling and the Chi-square. Finally, the verification of the identified models has been made using the data of the confirmatory period, 2005-2015, where conclusions are drawn concerning their prediction performance.

Table 1. The values of the parameters PI and the frequency of rainy days of each one upper-air synoptic circulation type, for the period 1958-2004.

\begin{tabular}{lllllllllll}
\hline & \multicolumn{8}{c}{ UPPER-AIR SYNOPTIC CIRCULATION TYPES } \\
\cline { 2 - 12 } & ZON & NW & L-1 & L-2 & L-3 & SW & H-1 & H-2 & $\mathbf{\Omega}$ & H-L \\
\hline PI & 0.63 & 0.47 & 0.96 & 1.25 & 1.23 & 1.02 & 0.62 & 0.37 & 0.65 & 0.73 \\
\hline FREQUENCY & $3 \%$ & $5 \%$ & $21 \%$ & $19 \%$ & $10 \%$ & $31 \%$ & $3 \%$ & $0 \%$ & $1 \%$ & $8 \%$ \\
\hline
\end{tabular}




\section{RESULTS}

\section{RELATIONSHIP BETWEEN RAINFALL} AND CIRCULATION TYPES

The values of the parameters PI and the frequency of rainy days for each upper-air synoptic circulation type are calculated for the total of rainy days, as well as, for each month, separately. Their values for the period 19582004 are shown in Table 1. The parameter PI shows values up to 1 for the types L-1, L-2, L3 and SW. At the same time, these types show the highest values of frequencies of rainy days. Similar results have drawn from the calculation of the parameters on a monthly basis (not shown).

For theaforementioned upper-air synoptic circulation types, the rainfall characteristics and their trends are studied. Table 2 depicts the statistical measures which characterize the rainfall distribution of the main upper-air synoptic circulation types, for the period 19582004. It is obvious that the rainfall behavior is different from one type to another. The rainfall indicates intense variability and higher rainfall measures during the prevalence of L-2 and L3 upper-air synoptic circulation types. The rainfall shows inhomogeneous characteristics on a monthly basis,during their prevalence. The trends are calculated using the linear regression and are characterized as statistically significant at the $95 \%$ confidence level.

Table 2. Statistical measures characterizing the rainfall distribution of the main upper-air synoptic circulation type, for the period 1958-2004.

\begin{tabular}{llllll}
\hline $\begin{array}{l}\text { Circulation } \\
\text { types }\end{array}$ & Mean & $\begin{array}{l}\text { Standard } \\
\text { deviation }\end{array}$ & Median & $\begin{array}{l}\text { Coefficient of } \\
\text { skewness }\end{array}$ & $\begin{array}{l}\text { Coefficient of } \\
\text { kurtosis }\end{array}$ \\
\hline L-1 & 4.7 & 5.9 & 2.6 & 2.8 & 12.6 \\
\hline L-2 & 6.1 & 8.5 & 3.3 & 3.7 & 21.9 \\
\hline L-3 & 6.0 & 9.6 & 2.4 & 3.4 & 22.1 \\
\hline SW & 5.0 & 6.9 & 2.8 & 3.3 & 14.6 \\
\hline
\end{tabular}

Table 3 depicts the trends of the rainfall characteristics of the main upper-air synoptic circulation types, for the period 1958-2004. The upper-air synoptic circulation types L-1 and L-2 show positive trends for the three measures, with the highest values being displayed in the total rainfall (Table 3). This implies an increase in frequency of their rainy days, as well as, in the daily rainfall amounts. For L-3 and SW, the behavior of the above features seems to be different. It is worth pointing out the negative trends in the SW type. That is in its occurrence and in its contribution of the total rainfall recorded in the study months. Statistically significant trends of these characteristics $(\alpha=0.05)$ are those of rainy days frequencies of L-2 and SW types. However, from the study of the trends of the above characteristics on a monthly basis, significant conclusions are drawn for the variability of precipitation by synoptic type.

Table 3. Trends of rainfall characteristics of the main upper-air synoptic circulation type, for the period 1958-2004.

\begin{tabular}{llll}
\hline $\begin{array}{l}\text { Circulation } \\
\text { type }\end{array}$ & $\begin{array}{l}\text { Trend of rain } \\
\text { days' frequency }\end{array}$ & $\begin{array}{l}\text { Trend of mean } \\
\text { daily rainfall }\end{array}$ & $\begin{array}{l}\text { Trend of rainfall } \\
\text { totals }\end{array}$ \\
\hline L-1 & 0.080 & 0.010 & 0.530 \\
\hline L-2 & $0.113^{* *}$ & 0.010 & 0.760 \\
\hline L-3 & 0.046 & -0.061 & 0.043 \\
\hline SW & $-0.240^{* *}$ & 0.030 & -0.690 \\
\hline
\end{tabular}

\section{PROBABILITY DISTRIBUTIONS AND} UPPER-AIR CIRCULATION TYPES

For the determination of best fit theoretical probability function for the main upper-air synoptic circulation types, statistical tools (goodness of fit tests) have been adopted. The results of the statistical test scores and the best fit models are presented in Table 4. For the determination of the best fit model, the probability distributions, which are proposed 
as the second best fit models for the tests, have been tested, too. The results reveal that in many cases there was very little difference between and among the various distributions. For this reason, verification measures (correlation coefficient, mean absolute error (MAE), mean square error (MSE), etc) have been calculated for the selection of the best fit probability model(s) of the daily rainfall for main upper-air synoptic circulation types. The tests' results and the preferable choices of the best models are briefly described for each one of the main upper-air synoptic circulation types.

Table 4. Rainfall Distribution Models, proposed by the goodness of fit tests for each upper-air synoptic circulation type $(\mathrm{a}=0.05)$.

\begin{tabular}{lllllll}
\hline & \multicolumn{2}{c}{$\begin{array}{c}\text { Kolmogorov-Smirnov } \\
\text { test }\end{array}$} & \multicolumn{2}{c}{$\begin{array}{c}\text { Anderson-Darling } \\
\text { test }\end{array}$} & \multicolumn{2}{c}{$\mathrm{X}^{2}$} \\
test
\end{tabular}

- The Open Long Wave trough (L-1) case The three goodness of fit tests suggest three different distributions, as they are presented in Table 4. All of them are widely known distributions for their application in relative studies in different regions. The Gamma and Burr distributions have been proposed as the second best fit distributions. The overall five distributions models are depicted in Figure 2a, where they are compared against the actual measurements. It becomes obvious that the Gamma probability distribution function is very close to the "1-1" line, which corresponds to cases where the actual measurements are identical to the model estimations, for the

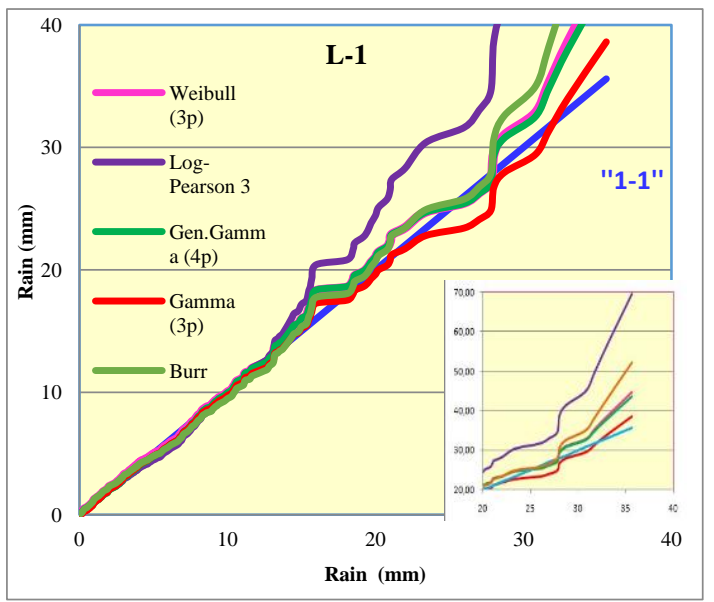

period 1958-2004. For the same period (19582004), the probability distribution functions of the Gamma, Burr and Generalized Gamma models are also quite close to the "1-1" line. The evaluated performance of the resulted best model, that is the Gamma model, is presented in Figure $2 b$, for the verification period of 2005-2015. The calculated verification measures of all the examined probability distribution models are indicated in Table 5, for the upper-air synoptic circulation L-1 type. It is worth noticing the higher values of correlation coefficient and the lower values of MAE and MSE, for the resulted best model, Gamma.

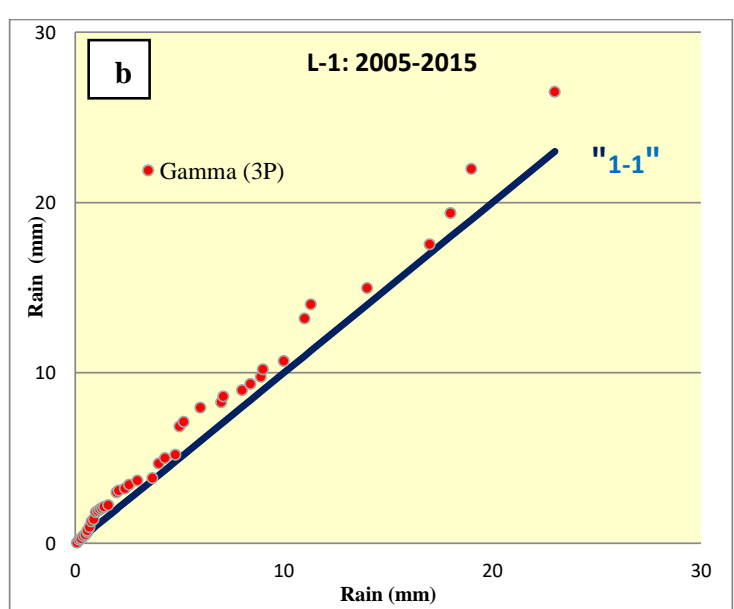

Figure 2: Comparison of the precipitation amounts of the Larissa station a) for the period 1958-2004 with the estimations of the proposed distribution models and b). For the period 2005-2015 with the estimations of Gamma model for the L-1 circulation type. 
- The Closed Long Wave trough (L-2) case The most appropriate probability distributions for the upper-air synoptic circulation type L-2, according to the to the three goodness of fit tests (Table 4), are the Generalized Gamma (4P) and Burr models. Moreover, the Gamma (3P) and Generalized Pareto distributions, are proposed as secondary appropriate models. From the comparison procedures between the actual measurements and models' estimations, the Burrand the Generalized Pareto models appear to be the best ones. Although the calculated verification measures are very close among them, the Generalized Pareto distribution model is proposed as the best fit model for the L-2, due to its simple and comprehensive probability distribution function (Table 6).

Table 5. Verification measures for the proposed models of the L-1 circulation type.

\begin{tabular}{llllll}
\hline Verification measures & Weibull & LogPearson 3 & Gen.Gamma (4P) & Gamma (3P) & Burr \\
\hline RMSE & 1.072 & 4.440 & 0.722 & 0.572 & 1.785 \\
\hline R & 0.995 & 0.971 & 0.996 & 0.997 & 0.985 \\
\hline MAE & 0.473 & 1.720 & 0.470 & 0.306 & 0.639 \\
\hline MSE & 1.150 & 19.711 & 0.521 & 0.328 & 3.186 \\
\hline
\end{tabular}

- Cut-Off Low (L-3) case

For the selection of the best fit distribution model, except for the three models shown in Table 4, the distribution function of Weibull has been tested as secondary appropriate model proposed by the Kolmogorov-Smirnov test. The calculated verification measures suggest that the Fatigue Life and Weibull probability distribution functions are the best models. However, the Weibull probability distribution model is proposed as the most appropriate for the synoptic type L-3 (Table 6), since it is easier to be used, due to its simple distribution function.

\section{- South-West flow (SW) case}

For the synoptic type SW, the selection of the most suitable model among the resulted, Gamma, Burr, Weibull, Generalized Gamma and Generalized Pareto probability distribution functions, is the Generalized Pareto model, since it has smallest error values (Table 6).

Table 6. The best fit probability distribution models for each upper-air synoptic circulation type.

\begin{tabular}{lll}
\hline $\begin{array}{l}\text { Circulation } \\
\text { type }\end{array}$ & Distribution models & Parameters \\
\hline L-1 & Gamma(3P) & $\begin{array}{l}\text { Shape: } \alpha=0.63316 \text { Scale: } \\
\beta=7.0782, \text { Location: } \gamma=0.1\end{array}$ \\
\hline L-2 & $\begin{array}{l}\text { Generalized } \\
\text { Pareto }\end{array}$ & $\begin{array}{l}\text { Shape: } \mathrm{k}=0.24253, \text { Scale: } \sigma=4.8736 \\
\text { Location: } \mu=-0.33123\end{array}$ \\
\hline L-3 & Weibull (3P) & $\begin{array}{l}\text { Shape: } \alpha=0.6403 \text { Scale: } \beta=4.2549 \\
\text { Location: } \gamma=0.1\end{array}$ \\
\hline SW & Generalized & $\begin{array}{l}\text { Shape: } \mathrm{k}=0.2645 \text { Scale: } \sigma=3.7998 \\
\text { Location: } \mu=-0.19565\end{array}$ \\
\hline
\end{tabular}

\section{VERIFICATION OF MODELS FOR EACH CIRCULATION TYPE}

An attempt is made to verify and confirm the resultedprobability distribution models presented on Table 6 , for the confirmatory period of 2005-2015, for each upper-air synoptic circulation type.

Using the rainfall data information for the confirmatory period, the Gamma probability distribution model appears to be a reasonable one for the L-1 upper-air synoptic circulation type. This is indicated in Figure 2b, where a slight overestimation of the rainfall amount becomes obvious. This is probably due to the encountered lower rainfall amounts compared to the exploratory period of 1958-2004. In spite of that, the Gamma probability distribution model is an efficient model of rainfall for the L-1 synoptic type.

For the L-2 upper-air synoptic circulation type, the proposed Generalized Pareto probability distribution model was applied to the observed 
data information of the confirmatory period 2005-2015. The comparison procedure indicated an overestimation of rainfall amounts up to $7 \mathrm{~mm}$ (not shown). In order to optimize the rainfall prediction, statistical tests of homogeneity (Bartlett, Levene, MannWhitney, Kruskal-Wallis, Kolmogorov etc.) have been performed for each one of the study months. The resulted best fit probability distributions models are demonstrated on Table 7, which provide better predictions over the confirmatory period than the only one model derived for the exploratory period.

Table 7. The best fit probability distribution models for each upper-air synoptic circulation type and for all the homogeneous sub-periods, over the verification-confirmation period (2005-2015).

\begin{tabular}{|c|c|c|c|}
\hline Circulation type & Months & Distribution models & Parameters \\
\hline \multirow[t]{3}{*}{ L-1 } & & & Shape: $\alpha=0.63316$ \\
\hline & & $\operatorname{Gamma}(3 \mathrm{P})$ & Scale: $\beta=7.0782$ \\
\hline & & & Location: $\gamma=0.1$ \\
\hline \multirow[t]{7}{*}{ L-2 } & & & Shape: $\mathrm{k}=0.03807$ \\
\hline & February -March & GeneralizedPareto & Scale: $\sigma=4.5302$ \\
\hline & & & Location: $\mu=-0.34098$ \\
\hline & & & Shape: $\alpha=0.75459$ \\
\hline & April -May & Gamma & Scale: $\beta=6.6944$ \\
\hline & & Gamma & Shape: $\alpha=0.81686$ \\
\hline & October, December & Gamma & Scale: $\beta=7.6$ \\
\hline \multirow[t]{5}{*}{ L-3 } & & & $\alpha=1587.2$ \\
\hline & October-November & Log Pearson-3 & $\beta=-0.03666$ \\
\hline & & & $\gamma=58.678$ \\
\hline & & & Shape: $\alpha=0.76221$ \\
\hline & March-April & Gamma & Scale: $\beta=3.0603$ \\
\hline \multirow[t]{5}{*}{ SW } & & & Shape: $\kappa=0.98756$ \\
\hline & January-May & GeneralizedGamma & $\alpha=0.85466$ \\
\hline & & & Scale $: \beta=5.209$ \\
\hline & December & Gamma & Shape: $\alpha=0.81438$ \\
\hline & December & & Scale: $\beta=7.8936$ \\
\hline
\end{tabular}

Concerning the L-3 synoptic types and applying the Weibull model to the confirmatory period $2005-2015$, it showed an overestimation on the rainfall amount from 18 to $30 \mathrm{~mm}$. In order to improve the prediction results, homogeneity tests were carried out and specific models were derived for the homogeneous months. Hence, the Log Pearson-3 and the Gamma models appear to be the most suitable ones for the month periods October-November and March-April, respectively (Table 7 ). It should be noted that the proposed Gamma model underestimates the predicted amounts up to $6 \mathrm{~mm}$.

Finally, for the type SW, the Generalized Pareto model seems to overestimate the rainfall amounts up to $15 \mathrm{~mm}$ for the verification period, probably due to the negative trend encountered for this circulation type. By applying the homogeneity test, it appears that the month periods January-May and October-December show similar characteristics,respectively. Hence, two new models were proposed as the most appropriate ones for these periods of the confirmatory stage: The Generalized Gamma and the Gamma models, respectively. The encountered overestimation of rainfall amounts up to $15 \mathrm{~mm}$ could be attributed to a negative trend of rainy days and rainfall amounts recorded at the meteorological station of Larissa.

\section{CONCLUSIONS}

The objective on this study is to model the daily rainfall in the region of Thessaly-Greece, based on the prevailing upper-air synoptic circulation types of the atmosphere. Classified the rainfall episodes of the period 1958-2015 into ten (10) upper-air synoptic circulation types, based on a subjective synoptic classification scheme, the relationships, between and among, these upper-air synoptic circulation types and the associated rainfalls 
are studied and their characteristics are presented. The main upper-air synoptic circulation types, which are quite favorable to rainfall activities at the examined meteorological station of Larissa, appeared to be: the open Long Wave trough (L-1), the closed Long Wave trough (L-2), the Cut-Off Low (L-3) and the South-West flow (SW). For these types, best fit probability distributions models have been determined for the prediction of daily rainfall data in the region of Thessaly. Based on the characteristics of models and their verification results, the following conclusions are drawn.

The L-1 type was the easiest type to study and estimate its rainfall amounts, probably due to the homogeneity of the data over the study months. Applying the proposed Gamma model to the rainfall amounts over the verification period, it showed its ability to reproduce satisfactorily the behavior of the examined variable.

Concerning the synoptic type of closed low (L2 ), the Generalized Pareto model was chosen as the most appropriate one for the exploratory period, while the models Generalized Pareto and Gamma for specific sub-periods of the verification period, due to inhomogeneity problems.

For the synoptic type of the cut-off low (L-3), the Weibull probability distribution was proven the most appropriate model to estimate the rainfall amounts for the verification period (1958-2004), while the Log-Pearson 3 and the Gamma reproduced satisfactorily the rainfall behavior for specific sub-periods over the verification period (2005-2015), due to inhomogeneity problems.

Concerning the southwest circulation, the results are completely different. The weakness of the Generalized Pareto model led to a further study of the study months in terms of the degree of homogeneity. None of the proposed distribution models approximates the behavior of the rainfall during the period 20052015. The suggested Generalized Gamma and Gamma models tend to overestimate the rainfall amounts over the sub-periods of the confirmatory period. The encountered overestimation of rainfall amounts could be attributed to a noticeable negative trend of rainy episodes and rainfall amounts.

\section{REFERENCES}

[1] Anagnostopoulou, C., Tolika. K., Maheras, P. Classification of Circulation Types: A New Flexible Automated Approach Applicable to NCEP and GCM Datasets. Theoreticaland Applied Climatology, DOI 10.1007/s00704-008-0032-6, 96,3-15,2009.

[2] Brunetti, M., M. Maugeri, T. Nanni. Atmospheric circulation and precipitation in Italy for the last 50 years. International Journal of Climatology22: 1455-1471, 2002.

[3] Buishand, T.A. Some remarks on the use of daily rainfall models. J. Hydrol., 36, 295-308, 1978.

[4] Burgueño, A., M.D. Martínez, X. Lana and C. Serra. Statistical distributionsif the daily rainfall regime in Catalonia (Northeastern Spain) for the years 1950-2000. Int. J. Climatol., $25,1381-1403,2005$.

[5] Duan, J., A.K. Sikka and G.E. Grant. A comparison of stochastic models for generating daily precipitation at the H.J. Andrews Experimental Forest., Northwest Science, 69 (4), 318 - 329, 1995.

[6] Feidas, X., Ch. Noulopoulou, T. Makrogiannis and E. Bora-Senta. Trend analysis of precipitation time series in Greece and their relationship with circulation using surface and satellite data: 1955-2001., Theoretical and Applied Climatology, 87, 155-177, 2007.

[7] Frei, C., C. Schör, D. Lüthi, H.C. Davies. Heavy precipitation processes in the warmer climate. Geophysical Research Letters,25, 1431-1434, 1998.

[8] Goodess, C.M. and J.P. Palutikof. Development of daily rainfall scenarios for southeast Spain using a circulation-type approach to downscaling., International Journal of Climatology, 18, 1051-1083, 1998.

[9] Goodess C.M. and P.D. Jones. Links between circulation and changes in the characteristics of Iberian rainfall. International Journal of Climatology, 22, 1593-1615, 2002. 
[10] Hess P., Brezowsky H. Katalog der GroßwetterlagenEuropas (1881-1976). Berichtedes Deutschen Wetterdienstes 15(113): Selbstverlag des Deutschen Wetterdienstes, Offenbach am Main, Germany, 1977.

[11] Karacostas, T., Flocas A.A., Flocas H.A., Kakaliagou O. and Rizou C. A study of thesynoptic situations over the area of Eastern Mediterranean. Proceedings, 1st Greek Conf.On Meteorology-Climatology-Physics of the Atmosphere, 21-23 May, Thessaloniki,Greece, pp 469-477 (in Greek), 1992.

[12] Karacostas, T. S., 2003: Synoptic, dynamic and cloud microphysical characteristics related to precipitation enhancement projects. 194-200. In: Regional Seminar on Cloud Physics and weather modification. World Meteorological Organization, WMP No. 42, WMO-TD No. 1227, 213pp.

[13] Karacostas Th., D. Bampzelis, S. Karipidou, I. Pytharoulis, I. Tegoulias, S. Kartsios, S. Kotsopoulos, and N. Pakalidou. Comparative analysis of near-present and future synoptic conditions and their contribution to precipitation in central Greece. In Proc.: European Geosciences Union (EGU) General Assembly 2015, Vienna, Austria, 12-17 April.

[14] Krichak, S.O., Tsidulko M, Albert P. Monthly synoptic patterns associated with wet/dry conditions in the eastern Mediterranean. Theoretical and Applied Climatology 65: 215-229, 2000.

[15] Lamb H.H. British Isles weather types and a register of the daily sequence ofcirculation patterns, 1861-1971. In Geophysical Memoirs, London., Vol. 116,1972.

[16] Maheras P. Synoptic situations causing draught in the Mediterranean basin. In: Vogt J.V., Somma F. (eds) Drought and drought mitigation in Europe. Netherlands: Kluwer Academic Press, pp 91-102, 2000.

[17] Maheras, P., K. Tolika, C. Anagnostopoulou, M. Vafiadis, I. Patrikas and H. Flocas. On the relationships between circulation types and changes in rainfall variability in Greece International Journal of Climatology,.24: 1695-1712., 2004.

[18] Michailidou, C. P., Maheras, A., Arseni-Papadimititriou, F., Kolyva-Machera, Anagnostopoulou, C. A study of Weather Types at Athens and Thessaloniki and their relationship to Circulation Types for the Cold-Wet period. Part I: Two-Step Cluster Analysis, Theoretical and Applied Climatology, 97, 163-177, 2009.

[19] Muller R.A. A synoptic climatology for environmental baseline analysis: New OrleansJournal of Applied Meteorology, 16: 20-33, 1977.

[20] Parker, D.E., P.D. Jones, C.K. Folland, A. Bevan. Interdecadal changes of surface temperature since the late nineteenth century., Journal of Geophysical Research,99, 14 37314 399, 1994.

[21] Steinberger, E.H. and N. Gazit-Yaari. Recent changes in the spatial distribution of annual precipitation in Israel., Journal of Climate,9, 3328-3336,1996.

[22] Thom, H.C.S., 1951: A frequency distribution for precipitation., Bull. Amer. Meteorol. Soc., 32(10), 397, 1996.

[23] Türkeş, M. Influence of geopotential heights, cyclone frequency and southern oscillation on rainfall variations in Turkey., International Journal of Climatology, 18, 649-680, 1998.

[24] Wilks, D.S. Multi-site generalization of a daily stochastic precipitation model., J. Hydrol,. 210, 178-191,1998.

[25] Woolhiser, D.A. and J. Roldan. Stochastic daily precipitation models: 2. A comparison of distribution amounts., Water Resour. Res., 18 (5), 1461 - 1468, 1982. 